\title{
Determining initial and follow-up costs of cardiovascular events in a US managed care population
}

\author{
Richard H Chapman ${ }^{1 *}$, Larry Z Liư ${ }^{2,3}$, Prafulla G Girase ${ }^{1}$, Robert J Straka ${ }^{4}$
}

\begin{abstract}
Background: Cardiovascular (CV) events are prevalent and expensive worldwide both in terms of direct medical costs at the time of the event and follow-up healthcare after the event. This study aims to determine initial and follow-up costs for cardiovascular (CV) events in US managed care enrollees and to compare to healthcare costs for matched patients without CV events.

Methods: A 5.5-year retrospective matched cohort analysis of claims records for adult enrollees in 90 US health plans. Patients hospitalized for first CV event were identified from a database containing a representative sample of the commercially-insured US population. The CV-event group $(n=29,688)$ was matched to a control group with similar demographics but no claims for CV-related events. Endpoints were total direct medical costs for inpatient and outpatient services and pharmacy (paid insurance amount).

Results: Overall, mean initial inpatient costs were US dollars (\$) 16,981 per case (standard deviation [SD] = $\$ 20,474$ ), ranging from $\$ 6,699$ for a transient ischemic attack (mean length of stay [LOS] $=3.7$ days) to $\$ 56,024$ for a coronary artery bypass graft (CABG) (mean $L O S=9.2$ days). Overall mean health-care cost during 1-year followup was $\$ 16,582$ ( $S D=\$ 34,425)$, an excess of $\$ 13,792$ over the mean cost of matched controls. This difference in average costs between CV-event and matched-control subjects was $\$ 20,862$ and $\$ 26,014$ after two and three years of follow-up. Mean overall inpatient costs for second events were similar to those for first events $(\$ 17,705 /$ case; SD $=\$ 22,703)$. The multivariable regression model adjusting for demographic and clinical characteristics indicated that the presence of a CV event was positively associated with total follow-up costs $(P<0.0001)$.

Conclusions: Initial hospitalization and follow-up costs vary widely by type of CV event. The 1-year follow-up costs for CV events were almost as high as the initial hospitalization costs, but much higher for 2- and 3-year follow-up.
\end{abstract}

\section{Background}

Cardiovascular (CV) events are prevalent and expensive worldwide both in terms of direct medical costs at the time of the event and follow-up healthcare after the event. In 2006, the average cost at discharge for a Medicare beneficiary with a principal diagnosis of $\mathrm{CV}$ disease (CVD) was $\$ 10,201$ [1]. Continuing improvements in medical care make contemporary assessments of incremental CVD costs relevant and necessary for up-to-date economic analyses. In addition, it is important that health

\footnotetext{
* Correspondence: rchapman@us.imshealth.com

'US Health Economics \& Outcomes Research, IMS Health, Falls Church, VA, USA

Full list of author information is available at the end of the article
}

economic analyses consider the costs of specific $\mathrm{CV}$ events in addition to a broad assessment of CVD.

Given the lack of up-to-date cost estimates for specific $\mathrm{CV}$ events in the literature, we performed a retrospective, matched cohort analysis of transactional billing (claims) records to determine the cost of various specific $\mathrm{CV}$ events. This study assessed the differences in total direct medical costs for those with and without $\mathrm{CV}$ events while controlling for potential confounders and underlying differences that may exist among study groups as a means to assess the incremental cost of CV events over average health care costs. This study also examined cost differences between initial and subsequent CV events, as well as differences in costs among patients with comorbidities of
C Biomed Central

(c) 2011 Chapman et al; licensee BioMed Central Ltd. This is an Open Access article distributed under the terms of the Creative Commons Attribution License (http://creativecommons.org/licenses/by/2.0), which permits unrestricted use, distribution, and reproduction in any medium, provided the original work is properly cited. 
hypertension (HTN), type 2 diabetes mellitus (DM), and dyslipidemia (DYS).

The primary study objectives were to: determine overall costs of initial and subsequent $\mathrm{CV}$ events in patients who have been hospitalized with a CV event; examine costs of 1-, 2-, and 3-year follow-up care among all patients with a CV event; and determine incremental costs for $\mathrm{CV}$ events by comparing total costs of followup care for patients with a CV event to similar patients without a CV event.

\section{Methods}

\section{Ethical Approval}

Request to include details of the Institutional Review Board that granted ethical approval or any requirements for permission to use the data sets.

\section{Data}

Claims data were obtained from the IMS LifeLink: US Health Plan Claims data base (formerly called the PharMetrics Patient-Centric database), a nationally-representative longitudinal database containing fully adjudicated medical and pharmaceutical claims for $>50$ million unique patients participating in $>90$ commercial health plans across the US. The database includes: inpatient and outpatient diagnoses (as ICD-9-CM codes) and procedures (as CPT-4 and HCPCS codes), as well as retail and mail order prescription records. CV events and procedures of interest and the corresponding codes are shown in Table 1. Claims dates were available for all services rendered. Additional data include: demographic variables (age, gender, geographic region); product type (e.g., Health Maintenance Organization [HMO], Preferred Provider Organization [PPO]); payer type (e.g., commercial, self-pay); provider specialty; and start and stop dates for plan enrollment.

\section{Study Period}

The 5.5 year study period (including a 1-year identification period) ranged from January 1, 2001 to June 30, 2006. All patients with an index hospitalization for a CV event were identified for analysis. For these patients, readmission could occur during the follow-up period (up to June 30, 2006).

Study data were divided into 3 periods: identification, pre-index, and follow-up. The identification period was from January 1, 2001 through June 30, 2005. The first hospitalization with relevant diagnosis or procedure codes for a CV event during this period was designated as that patient's index event. If a hospitalization was associated with $>1$ diagnosis or procedure code of interest, the patient was included in each relevant event type; i.e., event types were not mutually exclusive. For example, if a patient was admitted for MI and then underwent
Table 1 Codes for CV events, co-morbid conditions and procedures

\begin{tabular}{ll}
\hline Diagnoses and Procedures & Codes \\
\hline Event & \\
ICD-9-CM \\
Heart failure with or without & $398.91,402.01,402.11,402.91$, \\
CKD & $404.01,404.03,404.11,404.13$, \\
& $404.91,404.93,428 . x x$ \\
Myocardial infarction & $410 . x x, 412$ \\
Unstable angina and angina & $411.1,413 . x$ \\
pectoris & \\
Other ischemic heart disease & $411 . x x$ (except 411.1, 414.xx, \\
& $427 . x x$, V45.81, V45.82 \\
Ischemic stroke & $433 . x x, 434 . x x, 436,437.0,437.1$, \\
& $438 . x x, 997.02$ \\
TIAs and other CVAs & $435 . x$ \\
Peripheral vascular disease & $440.0,440.1,440.2 x, 443 . x x$ \\
Co-morbid conditions & ICD-9-CM \\
Hypertension & $401 . x x, 401.0,401.1,401.9,402$. \\
& $x x, 403 . x x, 404 . x x, 796.2$ \\
Dyslipidemia & $272 . x x$ \\
Diabetes mellitus & $250 . x 0,250 . x 2,250 . x$ \\
& \\
Procedure & CPT-4 \\
CABG & $33503-33545$ \\
Coronary stenting & 92980,92981 \\
Percutaneous transluminal & $92973,92982,92984,92995$, \\
coronary angioplasty/ & 92996 \\
thrombectomy/atherectomy & \\
Percutaneous transluminal & 92997,92998 \\
pulmonary artery balloon & \\
angioplasty & \\
Carotid endarterectomy & $35301,35390,35901$ \\
\hline
\end{tabular}

CKD, chronic kidney disease; TIA, transient ischemic attack; CVA, cerebrovascular accidents; CABG, coronary artery bypass graft.

CABG, that patient would be included in both the MI and CABG categories. The date of first hospital discharge with a diagnosis or procedure code of interest served as the index date for that patient. The pre-index period was defined as 1 year (12 months) prior to index hospitalization admission date. Thus, beginning and ending dates of the pre-index period varied among patients with the earliest time at which the pre-index period could begin being January 2000. Three follow-up periods were used to create cohorts of patients with 12-, 24-, or 36-month continuous enrollment after discharge from the index hospitalization. Follow-up terminated at the end of the patient's enrollment period in the health plan or the study end date (June 30, 2006). Patients who died were included regardless of follow-up length. Because deaths are not available in the claims data (due to privacy concerns), a proxy algorithm was used to determine patient deaths; in brief, patients were assumed to have died if they had evidence of specific mortality-associated events during the last month in which medical and pharmacy 
claims were available prior to disenrollment. Thus, beginning and ending dates of the follow-up period varied among patients but could not extend beyond June 30, 2006.

Patients were tracked from admission for the index hospitalization (or index date for non-event patients) until the end of enrollment in the health plan or study end date, whichever came first. All records relating to the index hospitalization and subsequent follow-up from the index date were extracted for analysis. Data pertaining to the first CV event readmission in the follow-up period were also extracted for analyses.

\section{Patient Selection}

Subjects were stratified into two cohorts based on presence or absence of hospitalization for a CV event. The $\mathrm{CV}$-event group included all patients with a complete hospitalization (admission and live discharge within the identification period) containing relevant procedure or primary diagnosis codes for a $\mathrm{CV}$ event during the identification period. A matched control group was used to compare total follow-up costs between patients with and without CV events.

Exclusion criteria for both CV-event and control groups included: patient not continuously eligible for drug and health benefits during their entire pre-index and follow-up periods; health plan did not report days supplied or quantity dispensed for medications; patient $<18$ years of age at index; patient $\geq 65$ years of age whose insurance coverage was not "Medicare Risk" at any time during study period (complete claims histories may not be available for patients without Medicare Risk coverage due to benefit coordination issues with other payers); patient with evidence of pre-existing CVD (claims for $\mathrm{CV}$-related diagnoses or procedures in the pre-index period); or patient with index hospital stay of more than 27 days (99th percentile).

All records from the pre-index period, index event (first hospitalization for the $\mathrm{CV}$-event group and matched index date for the non-event group), and follow-up from the index date (to the end of June 2006) were extracted. Records were linked using a unique patient code. All medical, laboratory, and pharmacy claims were compiled for the period January 1, 2000 to June 30, 2006.

An index date was randomly assigned to control-pool subjects during their health plan enrollment which would guarantee collection of $\geq 1$ year of pre- and postindex data. Control-pool subjects were then matched with $\mathrm{CV}$-event subjects (on a 1:1 basis) by exact age, gender, exact year of index date, and follow-up duration (in 60-day bands). As the intent was to compare total costs of $\mathrm{CV}$-event follow-up to costs for an average patient, and not to determine incremental costs of $\mathrm{CV}$ events per se, patients were not matched on comorbid conditions. A diagram of the study cohort identification procedure is shown in Figure 1. In cases where a CVevent subject had $<12$ months of follow-up data due to death, they were matched with a control subject who also had $<12$ months of follow-up. In these cases, the index date for the CV-event subject was assigned to the control subject. All unsuccessfully matched control-pool subjects were excluded from the matched analyses.

Subjects with a CV event were also evaluated for evidence of HTN, DYS, or DM during the pre-index period. Subsets of subjects with $\geq 1$ of these three comorbidities of interest were created for analysis, with some subjects included in $>1$ subset. Subjects with HTN, DYS, or DM were identified by presence of relevant ICD-9 codes (Table 1). Diabetes was also identified by presence of any oral diabetes medication (with or without insulin).

For all CV-event subjects, we determined whether there were any subsequent $\mathrm{CV}$ events after the index hospitalization discharge. Subsequent events were determined by finding complete hospitalizations with relevant diagnosis or procedure codes of interest during the follow-up period. The number of subsequent events per subject and total medical costs associated with the first subsequent (ie. second) CV event were calculated.

\section{Measures of Interest}

Measures of interest for analysis included: subject demographic and clinical characteristics; number of subsequent $\mathrm{CV}$ events; total medical costs following index CV event; direct medical costs associated with the index hospitalization (total cost and LOS); direct medical costs of hospitalization associated with second CV event hospitalization (total cost and LOS); total all-cause follow-up medical costs after index hospitalization discharge; total CV-related follow-up costs after index hospitalization discharge (ie. claims for outpatient $\mathrm{CV}$ medications or CV-related procedures).

Total medical costs included all healthcare costs whether CV- or other-related. Direct medical costs included any cost incurred during the inpatient hospitalization associated with the $\mathrm{CV}$ event, ie. including co-pay. If a CV event was the primary diagnosis in any hospitalization (index or readmission), all costs from that hospitalization were attributed to that CV event and used in calculating total direct cost. Costs were summed from the admit date to the discharge date for hospitalizations. Costs were calculated based on allowed health plan payments for medications and services and expressed in 2006 US dollars (\$). Costs were also updated where necessary using the medical care component of the US Consumer Price Index. 


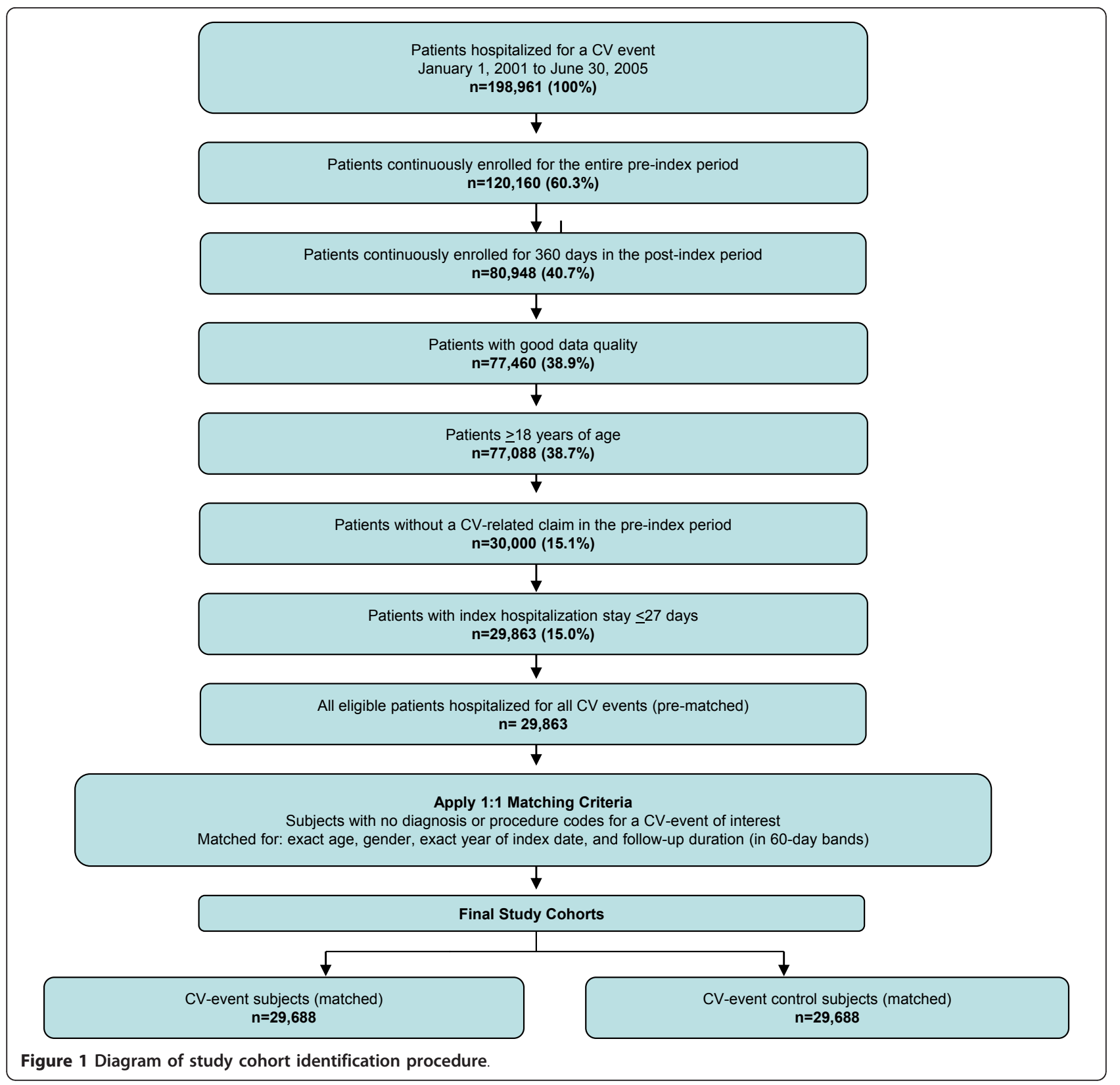

\section{Statistics}

Means, medians, and SDs for each cohort were calculated and reported for continuous variables. Distributions and frequencies were calculated for categorical variables. Overall subject characteristics were reported as well as for subject subsets (i.e., subjects with comorbid HTN, DYS, and/or DM).

Generalized linear models were used in main effects multivariable regression analyses of 1 -year follow-up costs to account for any remaining differences in variables used to match subjects and non-normally-distributed payments (common when using healthcare claims data). For the $\mathrm{CV}$-event group, the number of patients with a subsequent
$\mathrm{CV}$ event in the follow-up period was assessed, as well as the number of subsequent $\mathrm{CV}$ events per person-year of follow-up. Total direct medical costs and hospital LOS associated with initial and subsequent $\mathrm{CV}$ events were determined. The rate of subsequent $\mathrm{CV}$ events and costs associated with initial and subsequent $\mathrm{CV}$ events are reported overall as well for subsets with comorbid HTN, DYS, or DM.

Because this was a non-controlled observational study, it was expected that some degree of bias would exist among study groups. Matching non-CV event subjects and adjustments in multivariable analyses were used to control for these biases. The following subject-specific covariates were 
adjusted for in multivariable analyses: age group at index date; gender; health plan type (consumer-directed health care, HMO, indemnity, point of service [POS], PPO, other/unknown); health plan payer type (commercial, Medicaid, Medicare risk, self-insured, other/unknown); geographic region at index date (Northeast, Midwest, South, West); physician specialty at discharge from CV event hospitalization (family practice/general practitioner [FP/GP], internal medicine, cardiologist, other, unknown); Dartmouth Manitoba version of Charlson Comorbidity Index [CCI]; presence of DYS; presence of statin therapy or other lipid-lowering therapy in the pre-index period; presence of HTN; presence of type 2 DM; presence of other medications to treat comorbidities of $\mathrm{CV}$ disease; total health-care costs (i.e., payments by health plans to providers) during the 12-month pre-index period. Only main effects were considered; no interaction effects were assessed in the models.

The excess cost of a CV event during follow-up was estimated by comparing the total cost of care for CV-event subjects to costs for control (non-CV-event) subjects during follow-up. Resource utilization and costs were calculated for the first, second, and third years of follow-up. For this analysis only, we required subjects to have at least 12-, 24-, or 36-months of post-index data, as needed. Utilization and costs are reported by type of service and overall in the following categories: medications (CV-related therapies, all other medications); outpatient care (emergency room visits, physician office visits, imaging tests, laboratory procedures, all other outpatient services); inpatient care (number of hospitalizations, hospital LOS in days).

Along with total health-care costs, CV-related costs were also calculated. A claim was categorized as CVrelated if it was for diagnosis or procedure codes indicative of disease (as listed above), for statin therapy, or other lipid-lowering therapy, and for other concomitant CV medications.

All analyses were conducted using SAS $^{\circledR}$ version 8.02 (SAS Institute Inc., Cary, NC, USA).

\section{Results}

Of the 198,961 patients identified with an index hospitalization for a CV event between January 1, 2001 and June 30, 2005, the majority were excluded, predominantly for not fulfilling continuous enrolment requirements or for having a CV-related claim in the pre-index period (Figure 1). A total of 29,688 individuals met criteria to be $\mathrm{CV}$-event subjects and were matched with 29,688 control (non-CV-event) subjects. Among all (matched) CV-event subjects, mean (SD) age was 55.5 (12.0) years and $37.2 \%(11,097)$ were female. Baseline demographic and clinical characteristics for all matched subjects, as well as matched CV-event subjects and matched controls, are shown in Table 2.
Overall inpatient costs for index hospitalizations for CV-event subjects were $\$ 16,981$ per case $(S D=\$ 20,474$; median = \$9996) with an average (SD) length of stay of 4.36 (3.06) days. These costs varied considerably by type of CV event and ranged from a mean of $\$ 6699$ for TIA/ other CVAs and $\$ 6910$ for angina to $\$ 56,024$ for CABG. Mean LOS varied in a similar manner, from 2.71 days per angina hospitalization to 9.23 days for CABG (Table 3).

Mean overall costs for care in the first follow-up year were $\$ 16,582(\mathrm{SD}=\$ 34,425$; median $=\$ 7408)($ Table 4$)$. Overall mean follow-up costs increased to $\$ 26,644$ at 2 year follow-up and to $\$ 34,131$ at 3-year follow-up.

As expected, analysis of the matched cohort of CVevent versus control subjects found that mean total costs for year-1 follow-up healthcare were much higher for CV-event subjects $(\$ 16,582)$ than for those without CV events (\$2790) (Table 4), an excess of $\$ 13,792$ over matched controls' mean cost. Mean total healthcare costs in the year prior to the index CV event (\$5124) were lower than in the year following the CV event, but were still much higher than year-1 costs for matched control subjects without a CV event (Table 4). The gap between costs for CV-event subjects and matched control subjects was even larger when mean total costs were compared at 2-year $(\$ 26,644$ vs. $\$ 5782$ per subject, respectively) and 3-year follow-up (\$34,131 versus $\$ 8117$ per subject, respectively) (Table 4 , Figure 2). The difference in average costs between CV-event and matchedcontrol subjects was $\$ 20,862$ after 2 years and $\$ 26,014$ after 3 years of follow-up.

In the multivariable model of main effects adjusting for demographic and clinical differences between subjects, presence of a CV event was the strongest predictor of total 1-year follow-up costs $(\mathrm{P}<0.0001)$ (Table 5). Age, hypertension, hyperlipidemia, and diabetes, were also statistically significant predictors of increased costs. Payer type and geographic region were related to increased cost of $\mathrm{CV}$ events in some instances, but plan type and physician specialty had no significant association with follow-up costs.

Among the overall CV-event cohort, 4805 (16.1\%) patients experienced at least one subsequent CV event leading to hospitalization. The overall mean hospital length of stay was 4.85 days, with CABG having the greatest LOS at 8.87 days per event. The overall mean hospitalization cost for the subsequent CV event was only slightly higher than the overall mean cost per index event ( $\$ 17,709$ vs. $\$ 16,981$, respectively; data not shown). Differences in mean costs were generally within $\$ 3000$ or less of each other, with the largest absolute differences occurring for CABG $(\$ 46,236$ recurrent vs. $\$ 56,024$ initial) and other $\mathrm{CV}$ procedures $(\$ 19,023$ recurrent vs. \$26,254 initial). 
Table 2 Baseline demographic and clinical characteristics

\begin{tabular}{|c|c|c|c|}
\hline Demographic and Clinical Characteristics & $\begin{array}{l}\text { CV-Event Patients } \\
\text { (matched) }\end{array}$ & $\begin{array}{l}\text { CV-Event Control Patients } \\
\text { (matched) }\end{array}$ & P-value \\
\hline Total Subjects & 29,688 & 29,688 & \\
\hline Age, mean (years) & 55.5 & 55.4 & 0.5474 \\
\hline Age groups, \% & & & 0.9963 \\
\hline $18-34$ & 2.55 & 2.53 & \\
\hline $35-44$ & 11.46 & 11.55 & \\
\hline $45-54$ & 34.72 & 34.74 & \\
\hline $55-64$ & 38.05 & 37.94 & \\
\hline $65+$ & 13.22 & 13.23 & \\
\hline Gender, \% & & & 1.00 \\
\hline Female & 37.15 & 37.15 & \\
\hline Payer type at index, \% & & & $<0.0001$ \\
\hline Commercial Plan & 74.75 & 74.35 & \\
\hline Medicare & 1.10 & 0.50 & \\
\hline Medicaid Risk & 13.87 & 13.41 & \\
\hline Self-Insured & 4.92 & 5.88 & \\
\hline Unknown & 5.35 & 5.85 & \\
\hline Geographic Region at index, \% & & & $<0.0001$ \\
\hline Northeast & 19.26 & 22.31 & \\
\hline Midwest & 42.58 & 41.34 & \\
\hline South & 32.18 & 27.59 & \\
\hline West & 5.98 & 8.76 & \\
\hline Duration of follow-up, mean (days) & 696 & 696 & 0.7103 \\
\hline $\mathrm{CCl}$, mean & 0.56 & 0.27 & $<0.0001$ \\
\hline Pre-index presence of DYS, $\%$ & 30.12 & 22.08 & $<0.0001$ \\
\hline Pre-index presence of HTN, \% & 39.01 & 22.01 & $<0.0001$ \\
\hline Pre-index presence of $\mathrm{DM}, \%$ & 18.39 & 7.06 & $<0.0001$ \\
\hline Pre-index 12-month total healthcare costs (mean), \$ in 1000s & $\$ 5124$ & $\$ 2652$ & $<0.0001$ \\
\hline
\end{tabular}

$\mathrm{CV}$ = cardiovascular; $\mathrm{CCl}$ = Charlson Comorbidity index; DYS = dyslipidemia; HTN = hypertension; DM = diabetes mellitus.

\section{Discussion and Conclusions}

In this retrospective claims database analysis, we document the high costs for CV events and follow-up care (for 1 to 3 years) in a commercially-insured US population. In particular, mean healthcare costs among CVevent subjects were substantially higher in post-index years compared to control subjects. Among CV-event subjects, initial hospitalization costs varied widely by type of $\mathrm{CV}$ event ranging from $\$ 6,699$ for a TIA to $\$ 56,024$ for a CABG.

The 1-year follow-up costs for CV events were almost as high as the initial hospitalization costs, and were much higher at 2- and 3-year follow-up. These data are consistent with previous evidence showing that persons with CVD incur significantly greater direct medical costs than persons without CVD, with the annual

Table 3 Unadjusted costs of index hospitalization among all CV event subjects

\begin{tabular}{lcccccccccc}
\hline & Overall & CABG & $\begin{array}{c}\text { Other CV } \\
\text { Procedures }\end{array}$ & MI & $\begin{array}{c}\text { Heart } \\
\text { Failure }\end{array}$ & Angina & $\begin{array}{c}\text { Other Ischemic } \\
\text { Heart Disease }\end{array}$ & $\begin{array}{c}\text { Stroke } \\
\text { TIA/ } \\
\text { other } \\
\text { CVAs }\end{array}$ & $\begin{array}{c}\text { PVD } \\
\text { (n) }\end{array}$ \\
\hline Total patients $\mathrm{n}$ & 29,688 & 1894 & 8581 & 9151 & 2230 & 1650 & 11,224 & 2600 & 2317 & 164 \\
Cost of index & $\$ 16,981$ & $\$ 56,024$ & $\$ 26,254$ & $\$ 25,022$ & $\$ 12,052$ & $\$ 6910$ & $\$ 15,278$ & $\$ 12,365$ & $\$ 6699$ & $\$ 16,269$ \\
$\begin{array}{l}\text { hospitalization mean } \\
\text { (SD) }\end{array}$ & $(\$ 20,474)$ & $(\$ 33,207)$ & $(\$ 21,089)$ & $(\$ 24,857)$ & $(\$ 15,152)$ & $(\$ 7,585)$ & $(\$ 17,974)$ & $(\$ 12,667)$ & $(\$ 6,447)$ & $(\$ 19,831)$ \\
LOS, days mean (SD) & 4.36 & 9.23 & $4.08(2.41)$ & 4.68 & 5.59 & 2.71 & $3.82(2.67)$ & 5.44 & 3.78 & 6.99 \\
& $(3.06)$ & $(3.65)$ & & $(3.00)$ & $(3.59)$ & $(1.40)$ & & $(3.37)$ & $(2.83)$ & $(5.37)$ \\
\hline
\end{tabular}

$\mathrm{CABG}=$ coronary artery bypass graft; $\mathrm{MI}=$ myocardial infarction; $\mathrm{TIA}=$ transient ischemic attack; $\mathrm{CVA}=$ cerebrovascular accidents; $\mathrm{PVD}=$ peripheral vascular disease; LOS = length of stay.

Patients could be classified into $>1$ event type. 
Table 4 Unadjusted costs for CV-event and matched control groups at 1-, 2-, and 3-year follow-up

\begin{tabular}{|c|c|c|c|c|c|c|c|}
\hline \multirow[b]{2}{*}{ Resources Used } & \multirow{2}{*}{$\begin{array}{c}\text { Pre-Index } \\
\text { CV-Event } \\
(\mathrm{n}=29,688) \\
\text { mean (SD) } \\
\text { median }\end{array}$} & \multicolumn{2}{|c|}{ Year 1} & \multicolumn{2}{|c|}{ Years 1-2 } & \multicolumn{2}{|c|}{ Years 1-3 } \\
\hline & & $\begin{array}{c}\text { CV-Event } \\
(\mathrm{n}=29,688) \\
\text { mean }(\mathrm{SD}) \\
\text { median }\end{array}$ & $\begin{array}{c}\text { Control } \\
(n=29,688) \\
\text { mean }(S D) \\
\text { median }\end{array}$ & $\begin{array}{c}\text { CV-Event } \\
(\mathrm{n}=11,620) \\
\text { mean }(\mathrm{SD}) \\
\text { median }\end{array}$ & $\begin{array}{c}\text { Control } \\
(n=11,620) \\
\text { mean }(S D) \\
\text { median }\end{array}$ & $\begin{array}{c}\text { CV-Event } \\
(\mathrm{n}=3853) \\
\text { mean (SD) } \\
\text { median }\end{array}$ & $\begin{array}{c}\text { Control } \\
(\mathrm{n}=3853) \\
\text { mean }(\mathrm{SD}) \\
\text { median }\end{array}$ \\
\hline \multirow{2}{*}{$\begin{array}{l}\text { CV-related } \\
\text { medications }\end{array}$} & $\$ 285(\$ 619)$ & $\$ 813(\$ 1051)$ & $\$ 180(\$ 493)$ & $\$ 1676(\$ 1885)$ & $\$ 394(\$ 958)$ & $\$ 2530(\$ 2579)$ & $\$ 662(\$ 1426)$ \\
\hline & $\$ 0$ & $\$ 471$ & $\$ 0$ & $\$ 1,121$ & $\$ 0$ & $\$ 1757$ & $\$ 0$ \\
\hline \multirow{2}{*}{$\begin{array}{l}\text { All other } \\
\text { medications }\end{array}$} & $\$ 1135(\$ 4511)$ & $\$ 1917(\$ 5936)$ & $\$ 588(\$ 2423)$ & $\$ 3687(\$ 10,272)$ & $\$ 1273(\$ 4558)$ & $\$ 5064(\$ 11,456)$ & $\$ 1921(\$ 4932)$ \\
\hline & $\$ 149$ & $\$ 756$ & $\$ 20$ & $\$ 1,487$ & $\$ 139$ & $\$ 2166$ & $\$ 399$ \\
\hline \multirow[t]{2}{*}{ Emergency room } & $\$ 186(\$ 728)$ & $\$ 390(\$ 1593)$ & $\$ 68(\$ 447)$ & $\$ 704(\$ 2086)$ & $\$ 134(\$ 601)$ & $\$ 1113(\$ 2734)$ & $\$ 217(\$ 735)$ \\
\hline & $\$ 0$ & $\$ 0$ & $\$ 0$ & $\$ 0$ & $\$ 0$ & $\$ 96$ & $\$ 0$ \\
\hline \multirow{2}{*}{$\begin{array}{l}\text { Physician office } \\
\text { visit }\end{array}$} & $\$ 637(\$ 2442)$ & $\$ 1,248(\$ 3409)$ & $\$ 398(\$ 907)$ & $\$ 2145(\$ 6820)$ & $\$ 849(\$ 1550)$ & $\$ 2726(\$ 5710)$ & $\$ 1208(\$ 2016)$ \\
\hline & $\$ 301$ & $\$ 725$ & $\$ 178$ & $\$ 1335$ & $\$ 459$ & $\$ 1836$ & $\$ 719$ \\
\hline \multirow[t]{2}{*}{ Imaging tests } & $\$ 397(\$ 1624)$ & $\$ 858(\$ 2130)$ & $\$ 232(\$ 1252)$ & $\$ 1384(\$ 3125)$ & $\$ 435(\$ 1680)$ & $\$ 1616(\$ 2600)$ & $\$ 551(\$ 1627)$ \\
\hline & $\$ 12$ & $\$ 193$ & $\$ 0$ & $\$ 679$ & $\$ 40$ & $\$ 903$ & $\$ 91$ \\
\hline \multirow{2}{*}{$\begin{array}{l}\text { Laboratory } \\
\text { procedures }\end{array}$} & $\$ 187(\$ 628)$ & $\$ 356(\$ 1119)$ & $\$ 118(\$ 335)$ & $\$ 630(\$ 1810)$ & $\$ 256(\$ 607)$ & $\$ 783(\$ 1541)$ & $\$ 357(\$ 835)$ \\
\hline & $\$ 38$ & $\$ 144$ & $\$ 3$ & $\$ 317$ & $\$ 96$ & $\$ 451$ & $\$ 169$ \\
\hline \multirow{2}{*}{$\begin{array}{l}\text { All other } \\
\text { outpatient } \\
\text { services }\end{array}$} & $\$ 1384(\$ 5070)$ & $\$ 3692(\$ 9745)$ & $\$ 781(\$ 3125)$ & $\$ 6051(\$ 14,075)$ & $\$ 1640(\$ 6722)$ & $\$ 7826(\$ 17,797)$ & $\$ 2214(\$ 5018)$ \\
\hline & $\$ 127$ & $\$ 1321$ & $\$ 22$ & $\$ 2644$ & $\$ 239$ & $\$ 3600$ & $\$ 594$ \\
\hline \multirow[t]{2}{*}{ Hospitalization } & $\$ 912(\$ 7120)$ & $\$ 7308(\$ 27,680)$ & $\$ 424(\$ 4258)$ & $\$ 10,367(\$ 35,024)$ & $\$ 800(\$ 5082)$ & $\$ 12,473(\$ 34,671)$ & $\$ 986(\$ 5488)$ \\
\hline & $\$ 0$ & $\$ 0$ & $\$ 0$ & $\$ 0$ & $\$ 0$ & $\$ 0$ & $\$ 0$ \\
\hline \multirow[t]{2}{*}{ Total Care } & $\$ 5124(\$ 13,465)$ & $\$ 16,582(\$ 34,425)$ & $\$ 2790(\$ 7837)$ & $\$ 26,644(\$ 48,086)$ & $\$ 5782(\$ 12,807)$ & $\$ 34,131(\$ 51,331)$ & $\$ 8117(\$ 12,634)$ \\
\hline & $\$ 1917$ & $\$ 7408$ & $\$ 856$ & $\$ 13,761$ & $\$ 2622$ & $\$ 19,194$ & $\$ 4528$ \\
\hline
\end{tabular}

lifetime medical cost of treating CVD patients estimated to be 3.4 times greater than for patients without CVD $[2,3]$.

Our data were consistent with previous evidence that has shown that the costs of CV events and associated follow-up care in patients with HTN, DM, and DYS is higher than the overall mean healthcare costs for $\mathrm{CV}$ event subjects without a co-morbidity [4-9]. Previous analyses using the current database have shown that diabetic patients hospitalized for a cardiovascular event incur higher costs for overall cardiovascular care and for most types of individual cardiovascular events than their non-diabetic counterparts [10]. Other analyses have demonstrated that DM patients with cardiovascular comorbidity had significantly higher total healthcare costs (38.9\%; \$12,550 vs. \$9031), total Emergency Room (ER/ hospitalization costs (239.8\%; \$4845 vs. \$1426), total outpatient costs (35.3\%; $\$ 3956$ vs. $\$ 2925)$, and total prescription drug costs $(15.1 \%$; $\$ 4686$ vs. $\$ 4071)$ compared to DM patients without cardiovascular co-morbidity [11]. Similarly, uncontrolled HTN is estimated to result in 39,702 CV events, 8374 CVD deaths, and \$964 million in annual direct medical expenditures in the US [12].
The global burden of CVD is increasing and is expected to surpass infectious disease to become the world's leading cause of death and disability by the year 2020 [7]. The American Heart Association estimated the total annual direct medical expenditures for patients with CVD or stroke to be $\$ 131.3$ billion in 2008 [13], and recent analyses indicate that the actual economic burden to be substantially higher than this [14].

Because of the growing demand for scarce healthcare resources and the introduction of new, more expensive technologies, difficult choices must be made among competing therapeutic options and priorities [15,16]. Economic evaluation provides a means of rationally informing these choices so that the result is an efficient allocation of resources.

Accurate estimates of medical event costs are integral for pharmacoeconomic modeling. However, it is nearly impossible to accurately determine whether the clinical advantages of a novel CV therapy are likely to result in net cost-savings, for example due to reductions in events, procedures or hospital length of stay, if occurrence rates and costs for specific $\mathrm{CV}$ events are not known. 


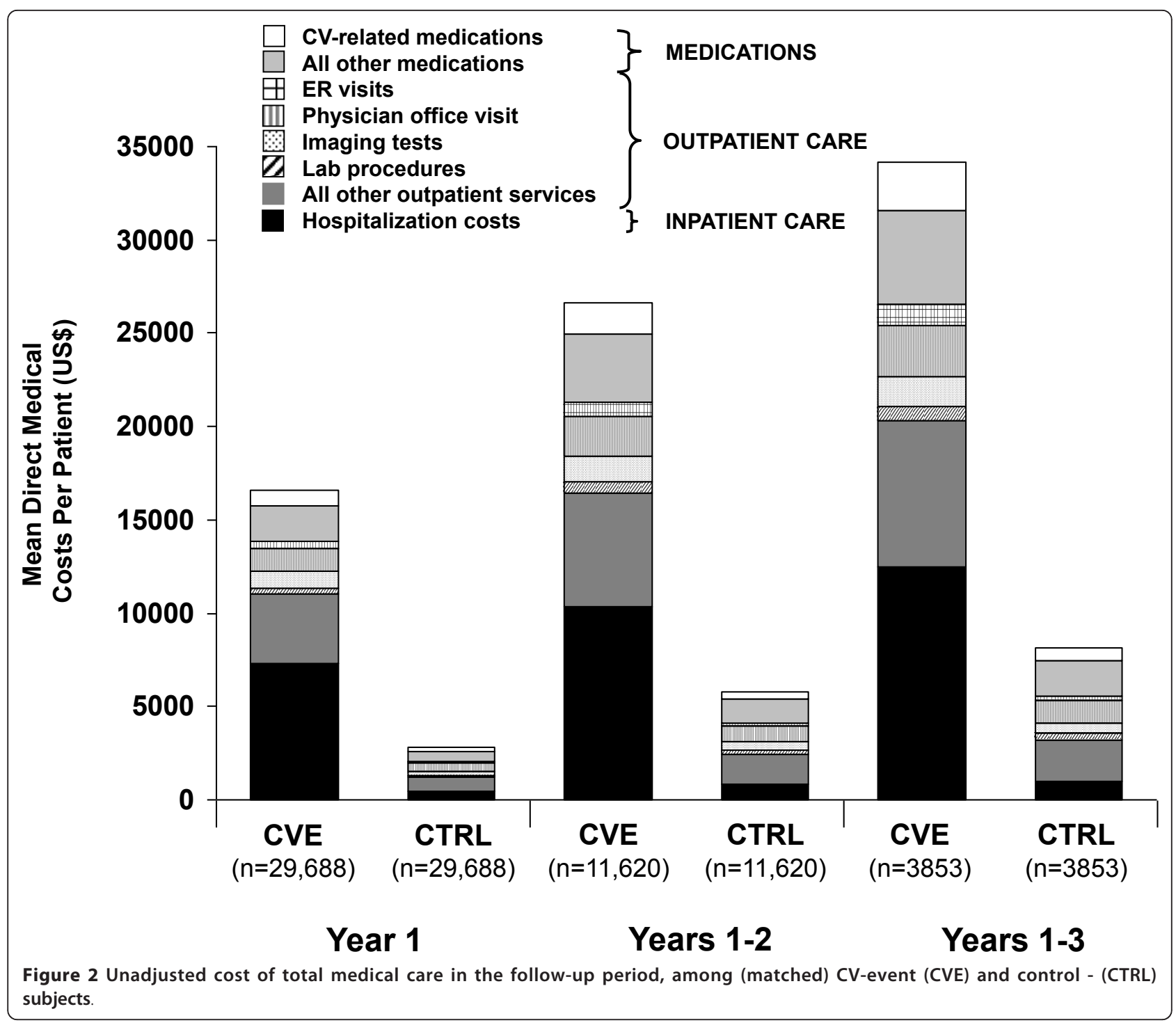

Since the claims analyses in this study were retrospective in nature, it is important to highlight some limitations in the interpretation of our findings. Accurate assessment of costs and resource utilization is heavily dependent on the correct allocation of diagnosis, procedure, and medication codes. In order that errors in the assignment of codes were minimal, all patient medical histories were subject to stringent data checks. In addition, only health-care plans that provided information for all members were included in the database, ensuring complete data capture and representative samples. In addition, as the costs reported here are derived from commercial managed care claims data, results may not be generalizable to other populations.

The multivariable model used was adjusted for the presence of DYS, HTN and DM. It is possible that inclusion of other co-morbidities may have affected the results of these analyses., Patients who died were included in our analyses as completed cases; however, patients who were lost to follow-up were excluded. Consequently, mean costs may have been biased towards patients who died soon after hospitalization. These patients may have incurred higher costs, as they may have been sicker and required more expensive treatment. Although our data precludes confirmation of this presumption, the estimates provided from our analysis remain a reasonable contemporary assessment of the costs within the limitations of our data set.

The findings from this study provide important estimates for pharmacoeconomic modeling of cardiovascular events, and are expected to benefit multiple stakeholders, including patients and policy-makers deciding how to most efficiently allocate healthcare resources. 
Table 5 Multivariable regression model comparing total costs following the index date

\begin{tabular}{|c|c|c|c|c|}
\hline Variable & Parameter Estimate & Standard Error & Chi-Square & P-value \\
\hline CV event: yes vs. no & 1.7546 & 0.0377 & 2169.7 & $<0.0001$ \\
\hline Hypertension: yes vs. no & 0.246 & 0.0158 & 241.0 & $<0.0001$ \\
\hline Hyperlipidemia: yes vs. no & 0.1425 & 0.0163 & 76.4 & $<0.0001$ \\
\hline Diabetes: yes vs. no & 0.34 & 0.0213 & 254.5 & $<0.0001$ \\
\hline $18-34$ years vs. $65+$ years & 0.5644 & 0.1162 & 23.6 & $<0.0001$ \\
\hline $35-44$ years vs. $65+$ years & 0.5521 & 0.1097 & 25.3 & $<0.0001$ \\
\hline $45-54$ years vs. $65+$ years & 0.7040 & 0.1083 & 42.3 & $<0.0001$ \\
\hline $55-64$ years vs. $65+$ years & 0.8720 & 0.1082 & 65.0 & $<0.0001$ \\
\hline Female: yes vs. no & 0.1792 & 0.0143 & 156. 7 & $<0.0001$ \\
\hline Plan type: HMO vs. Consumer-directed & 0.0194 & 0.1470 & 0.02 & 0.8948 \\
\hline Plan type: Indemnity vs. Consumer-directed & 0.1144 & 0.1490 & 0.6 & 0.4427 \\
\hline Plan type: PPO vs. Consumer-directed & 0.1540 & 0.1469 & 1.1 & 0.2943 \\
\hline Plan type: POS vs. Consumer-directed & 0.0564 & 0.1482 & 0.1 & 0.7036 \\
\hline Plan type: Other/Unknown vs. Consumer-directed & -0.1365 & 0.1585 & 0.7 & 0.3892 \\
\hline Payer type: Medicaid vs. Commercial & 0.376 & 0.0798 & 22.2 & $<0.0001$ \\
\hline Payer type: Medicare Risk vs. Commercial & 0.6435 & 0.1068 & 36.3 & $<0.0001$ \\
\hline Payer type: Self-insured vs. Commercial & -0.2372 & 0.0346 & 47.1 & $<0.0001$ \\
\hline Payer type: Other/Unknown vs. Commercial & -0.0627 & 0.0317 & 3.91 & 0.0481 \\
\hline Physician specialty: Internal medicine vs. FP/GP & 0.0242 & 0.0538 & 0.2 & 0.6529 \\
\hline Physician specialty: Cardiologist vs. FP/GP & 0.0857 & 0.0445 & 3.7 & 0.054 \\
\hline Physician specialty: Other vs. FP/GP & 0.0128 & 0.045 & 0.1 & 0.7752 \\
\hline Physician specialty: Unknown vs. FP/GP & 0.0587 & 0.0555 & 1.1 & 0.2899 \\
\hline Geographic region: Northeast vs. West & -0.107 & 0.0316 & 11.4 & 0.0007 \\
\hline Geographic region: Midwest vs. West & -0.0077 & 0.0292 & 0.1 & 0.7924 \\
\hline Geographic region: South vs. West & -0.106 & 0.0296 & 12.8 & 0.0003 \\
\hline
\end{tabular}

$\mathrm{HMO}=$ Health Maintenance Organization; PPO = Preferred Provider Organization; POS = Point of Service; FP/GP = family practitioner/general physician.

\section{Author details}

'US Health Economics \& Outcomes Research, IMS Health, Falls Church, VA, USA. ${ }^{2}$ Pfizer Inc., New York, NY, USA. ${ }^{3}$ Weill Cornell Medical College, New York, NY, USA. ${ }^{4}$ University of Minnesota College of Pharmacy, Minneapolis, MN, USA.

\section{Authors' contributions}

$\mathrm{RHC}$ contributed to the conception, design and co-ordination of the study, and participated in statistical analysis and programming, analysis and interpretation of the data, and development of the manuscript. LZL was involved in the conception and design of the study and participated in the analysis of the data and the development of the manuscript. PSG contributed to the design of the study and was involved in statistical analysis and programming. RJS participated in the analysis and interpretation of the data and was involved in the development of the manuscript. All authors read and approved the final manuscript.

\section{Competing interests}

This study was sponsored by Pfizer Inc. The topic of the study was agreed upon with Pfizer Inc at the outset of the project; however, the authors retained full rights in the design, analysis, interpretation, and publication of the results. RJS was a paid consultant to Pfizer Inc in connection with the development of this manuscript. PSG and RHC are employees of IMS Health, who were paid consultants to Pfizer Inc in the development of this manuscript. LZL is an employee of Pfizer Inc with ownership of stock in Pfizer Inc. Editorial support was provided by Dr John Bilbruck at UBC Scientific Solutions Ltd and Karen Trochlil and Katharine Coyle at IMS Health and was funded by Pfizer Inc.

Received: 7 May 2010 Accepted: 16 March 2011

Published: 16 March 2011

\section{References}

1. Lloyd-Jones D, Adams RJ, Brown TM, Carnethon M, Dai S, De Simone G, Ferguson TB, Ford E, Furie K, Gillespie C, et al: Heart disease and stroke statistics-2010 update: a report from the American Heart Association. Circulation 2010, 121(7):e46-e215.

2. Sasser AC, Rousculp MD, Birnbaum HG, Oster EF, Lufkin E, Mallet D: Economic burden of osteoporosis, breast cancer, and cardiovascular disease among postmenopausal women in an employed population. Womens Health Issues 2005, 15(3):97-108.

3. Birnbaum $\mathrm{H}$, Leong $\mathrm{S}$, Kabra A: Lifetime medical costs for women: cardiovascular disease, diabetes, and stress urinary incontinence. Womens Health Issues 2003, 13(6):204-213.

4. Daviglus ML, Liu K, Greenland P, Dyer AR, Garside DB, Manheim L, Lowe LP, Rodin M, Lubitz J, Stamler J: Benefit of a favorable cardiovascular risk- 
factor profile in middle age with respect to Medicare costs. N Engl J Med

1998, 339(16):1122-1129.

5. Daviglus ML, Liu K, Pirzada A, Yan LL, Garside DB, Greenland P,

Manheim LM, Dyer AR, Wang R, Lubitz J, Manning WG, Fries JF, Stamler J:

Cardiovascular risk profile earlier in life and Medicare costs in the last year of life. Arch Intern Med 2005, 165(9):1028-1034.

6. Huse DM, Song X, Ozminkowski RJ, Maguire J, Williams SA, Borok GM, McDonough K: Impact of rosuvastatin use on costs and outcomes in patients at high risk for cardiovascular disease in US managed care and medicare populations: A data analysis. Clin Ther 2006, 28(9):1425-1442.

7. Levenson JW, Skerrett PJ, Gaziano JM: Reducing the global burden of cardiovascular disease: the role of risk factors. Prev Cardiol 2002, 5(4):188-199.

8. Oster G, Thompson D, Edelsberg J, Bird AP, Colditz GA: Lifetime health and economic benefits of weight loss among obese persons. Am J Public Health 1999, 89(10):1536-1542.

9. Song X, Huse DM, Williams SA, Borok GM, McDonough K, Ozminkowski RJ: A projection of the impact of lipid-lowering therapy on high-risk employee disability and medical costs. J Occup Environ Med 2006, 48(10):1014-1022.

10. Straka RJ, Liu LZ, Girase PS, DeLorenzo A, Chapman RH: Incremental cardiovascular costs and resource use associated with diabetes: an assessment of 29,863 patients in the US managed-care setting. Cardiovasc Diabetol 2009, 8:53.

11. Mody R, Kalsekar I, Kavookjian J, lyer S, Rajagopalan R, Pawar V: Economic impact of cardiovascular co-morbidity in patients with type 2 diabetes. J Diabetes Complications 2007, 21(2):75-83.

12. Flack JM, Casciano R, Casciano J, Doyle J, Arikian S, Tang S, Arocho R: Cardiovascular disease costs associated with uncontrolled hypertension. Manag Care Interface 2002, 15(11):28-36.

13. Rosamond W, Flegal K, Furie K, Go A, Greenlund K, Haase N, Hailpern SM, Ho M, Howard V, Kissela B, Kittner S, Lloyd-Jones D, McDermott M, Meigs J, Moy C, Nichol G, O'Donnell C, Roger V, Sorlie P, Steinberger J, Thom T, Wilson M, Hong Y: Heart disease and stroke statistics-2008 update: a report from the American Heart Association Statistics Committee and Stroke Statistics Subcommittee. Circulation 2008, 117(4):e25-e146.

14. Nichols GA, Bell TJ, Pedula KL, O'Keeffe-Rosetti M: Medical care costs among patients with established cardiovascular disease. Am J Manag Care 2010, 16(3):e86-e93.

15. Fox P, Gazzaniga J, Karter A, Max W: The economic costs of cardiovascular disease mortality in California, 1991: implications for public health policy. J Public Health Policy 1996, 17(4):442-459.

16. Jonsson B: Measurement of health outcome and associated costs in cardiovascular disease. Eur Heart J 1996, 17(Suppl A):2-7.

\section{Pre-publication history}

The pre-publication history for this paper can be accessed here: http://www.biomedcentral.com/1471-2261/11/11/prepub

doi:10.1186/1471-2261-11-11

Cite this article as: Chapman et al:: Determining initial and follow-up costs of cardiovascular events in a US managed care population. BMC Cardiovascular Disorders 2011 11:11.

\section{Submit your next manuscript to BioMed Central and take full advantage of:}

- Convenient online submission

- Thorough peer review

- No space constraints or color figure charges

- Immediate publication on acceptance

- Inclusion in PubMed, CAS, Scopus and Google Scholar

- Research which is freely available for redistribution

Submit your manuscript at www.biomedcentral.com/submit
Biomed Central 